\title{
Choice-functional Series of Indefinite Pronouns and Hamblin Semantics
}

\author{
Igor Yanovich \\ Moscow State University
}

\section{Introduction}

\subsection{Haspelmath's (1997) Challenge}

Haspelmath (1997) poses a challenge for current theories of indefinites. Extensive data from 40 languages show there are too many differences between indefinite pronoun series to account for with the usual machinery for indefinites. We can take Russian as an example: there are 4 main Russian indefinite pronoun series in 1, 4 other well-established series are unlisted, and Bylinina \& Testelets (2004) discuss several new series that are in the course of grammaticalization now.

(1)

\begin{tabular}{|l|l|l|l|l|}
\hline interrogative & to & nibud' & libo & ni \\
\hline kto 'who' & kto-to & kto-nibud' & kto-libo & nikto \\
\hline čto 'what' & čto-to & čto-nibud' & čto-libo & ničto \\
\hline gde 'where' & gde-to & gde-nibud' & gde-libo & nigde \\
\hline kogda 'when' & kogda-to & kogda-nibud' & kogda-libo & nikugda \\
\hline kak'how' & kak-to & kak-nibud' & kak-libo & nikak \\
\hline kakoj 'what/which' & kakoj-to & kakoj-nibud' & kakoj-libo & nikakoj \\
\hline
\end{tabular}

\subsection{Kratzer \& Shimoyama (2002): Hamblin Pronouns}

Though differences between indefinite pronouns were not unnoticed by semanticists (cf., i.e., Farkas 2002), to my knowledge, there was only one explicit attempt to provide a principled explanation for Haspelmath's data: it is Kratzer \& Shimoyama (2002). The core of their proposal consists of two claims:

(2) K\&S1: bare indefinite roots denote Hamblin sets of alternatives, not sets. K\&S2: series markers are simple meaningless agreement morphemes.

The first claim is justified by Shimoyama's (2001) analysis for Japanese indeterminate pronouns. The second one is intended to capture differences between indefinite pronoun series. For a given pronoun, its morphology determines what kind of operators it can associate with. For instance, there may be Negative Concord indefinites, Interrogative Concord indefinites (familiar whwords), and even Universal and Existential Concord ones. So if node "Question" is assigned to a pronoun on Haspelmath's map, we should say that this pronoun carry $\mathrm{Q}$ feature, and similarly for other nodes or combinations of nodes. 
Let us elaborate some details of the Hamblin system of $\mathrm{K} \& \mathrm{~S}$. First, we turn pronoun roots meanings into Hamblin non-singleton sets, (3). Second, meanings for all other expressions are turned into singleton sets containing their usual meanings as the only member, (4). Third, we change our semantic rules into alternative-friendly ones, see (5) for Functional Application (see also Shan (2003) for the discussion of the Predicate Abstraction rule).

(3) [[who]]: $\lambda x \cdot \operatorname{human}(x)(w) \Rightarrow\{x: \operatorname{human}(x)(w)\}$.

(4) $[[$ boy $]]: \lambda x \cdot \operatorname{boy}(x)(w) \Rightarrow\{p: p=\lambda x \cdot \operatorname{boy}(x)(w)\}$

(5) Hamblin Functional Application (from K\&S 2002): If $\alpha$ is a branching node with daughters $\beta$ and $\gamma$, and $[[\beta]]^{\mathrm{w}, \mathrm{g}} \subseteq \mathrm{D}_{\sigma}$ and $[[\gamma]]^{\mathrm{w}, \mathrm{g}} \subseteq \mathrm{D}_{<\sigma \tau>\text {, }}$ then $[[\alpha]]^{\mathrm{w}, \mathrm{g}}=\left\{\mathrm{a} \in \mathrm{D}_{\tau}: \exists b \exists c\left[b \in[[\beta]]^{\mathrm{w}, \mathrm{g}} \& \mathrm{c} \in[[\gamma]]^{\mathrm{w}, \mathrm{g}} \& \mathrm{a}=\mathrm{c}(\mathrm{b})\right]\right\}$.

Proper sentence meanings for declarative sentences are not propositions, but singleton sets of propositions, for instance, $\{\lambda w$.slept $(J o h n)(w)\}$ for 'John slept'. If we do not have any alternative-inducing (that is, Hamblin) expressions in a sentence, a singleton set is the only possible outcome, given the FA rule in (5).

However, if we happen to have an alternative-inducing expression in our sentence, we may arrive at a non-singleton set of propositions at the end of the derivation. If we do, it means that the derivation has crashed. In order to prevent the crash, alternatives must be 'caught' by some alternative quantifier that takes a Hamblin non-singleton set and yields a singleton set. Here is an example of a Japanese generalized quantifier over alternatives, a word that combines with DPs and PPs that contain (possibly deeply embedded) indeterminate pronouns, and performs universal quantification "at a distance":

$$
[[m o]]^{\mathrm{w}, \mathrm{g}}=\left\{\lambda \alpha \lambda \mathrm{P} \lambda \mathrm{w}^{\prime} . \forall \mathrm{a}\left[(\mathrm{a} \in \alpha) \rightarrow \mathrm{P}(\mathrm{a})\left(\mathrm{w}^{\prime}\right)\right]\right\}, \alpha \text { a Hamblin set. }
$$

In effect, an alternative-inducing expression seems to scope at the position of the alternative quantifier it is associated with. Thus, though the association mechanism is not related to syntactic movement in any way, we may (informally) say that the relation between indeterminate pronouns and their operators resembles the relation between a $\mathrm{QR}$-ed $\mathrm{DP}$ and its trace.

There are two crucial details about the association between alternative quantifiers and alternative-inducing expressions as indefinite pronouns: 1) this association is insensitive to syntactic islands (unlike $Q R$ ), since no syntactic movement is involved at all: alternatives are just "passed up" during the semantic composition; 2) alternatives keep expanding just till they meet the first alternative operator on their way: such operators always map their input to singleton alternative sets, so they cannot preserve alternatives. Thus, association with alternative operators is not local in the usual syntactic sense, but is subject to the other type of locality: alternatives cannot escape the first operator they meet:

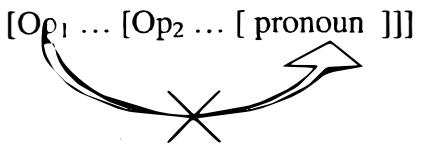


In this paper, I examine three series of indefinite pronouns in Russian. In Section 2, I argue that -to and -nibud' denote choice-functional variables, and thus are not just meaningless agreement morphemes. Thus, there prove to be two types of indefinite pronoun series: choice-functional (Russian) and Hamblin (Japanese), Section 3. In Section 4, I show that in fact Russian indefinite roots are as Hamblin as Japanese indefinite roots are, and that -to and -nibud' denote Hamblin choice functions. Thus K\&S's analysis for Japanese and my analysis for Russian CFseries are unified. Section 5 concludes the paper by mentioning at least some further problems on the way to a more comprehensive theory of indefinites.

\section{Choice-functional Series of Indefinite Pronouns}

\subsection{Russian -to Series: (Almost) Familiar Choice Functions}

(8) Kto-to vošel v komnatu.

Who-TO came into the room

'Someone came into the room.'

As (8) shows, -to pronouns are grammatical in simple declarative sentences. However, what is of much more interest is that -to indefinites (not only indefinite DPs, but AdjPs and AdvPs too) can scope out of scope islands ${ }^{1}$ :
a. Petja budet ščastliv esli kakaja-to devuška pridet.
Petja will be happy if which-TO girl will come
$\mathrm{OK}_{\exists}>$ if 'There is a property $\mathrm{p}_{\langle\mathrm{et}\rangle}$ such that Petja will be happy
if a girl y such that $\mathrm{p}(\mathrm{y})=1$ comes.'
$\mathrm{OK}_{\text {if }}>\exists \quad$ 'Pet ja will be happy if any girl comes.'
b. ... esli $\varnothing$ gde-to vstretit Mašu.
$\ldots$ if [he] where-TO will meet Masha
$\mathrm{OK}_{\exists}>$ if 'There is a place $\mathrm{x}_{\mathrm{e}}$ such that Petja will be happy
if he meets Masha at $x^{\prime}$
$\mathrm{OK}_{\text {if }}>\exists$ 'Pet ja will be happy if there is a place to meet Masha at'
c. ... esli $\varnothing$ kak-to smožet sdat' ekzamen.
... if [he] how-TO will be able to pass the exam
$\mathrm{OK}_{\exists}>$ if 'There is a manner $\mathrm{p}_{\langle\langle\mathrm{et}\rangle,\langle\mathrm{et}\rangle\rangle}$ such that Petja will be happy
if he manages to $\mathrm{p}$ (pass the exam)'
$\mathrm{OK}_{\text {if }}>\exists \quad$ 'Petja will be happy if he pass the exam in any manner'
d. ... esli kto-to smožet sdat' ekzamen.
... if who-TO will be able to pass the exam
$\mathrm{OK}_{\exists}>$ if 'There is a person $\mathrm{x}_{\mathrm{e}}$ such that Petja will be happy
if $x$ manages to pass the exam'
$\mathrm{OK}_{\text {if }}>\exists$ 'Petja will be happy if there is someone able to pass the exam' 


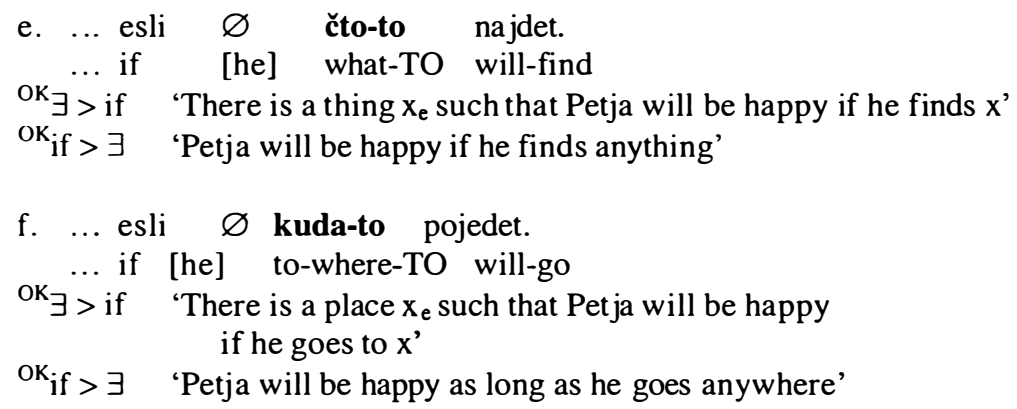

If an indefinite can escape from islands, there are two options: it can be either a CF indefinite (Reinhart 1997, Kratzer 1998) or a Hamblin indefinite (K\&S 2002). Which of the two do we have in the case of -to indefinites?

(Known) CF indefinites do not need licensing, and they can take the widest (pseudo-)scope; Hamblin indefinites need licensing from an alternative quantifier, and cannot take the widest pseudoscope (as a result of our interpretation procedure, they end up having a pseudoscope in the immediate scope of their licenser). (9) shows that -to can take the widest scope, and there is not any operator resembling an alternative quantifier in (8) and $(9)^{2}$. And it can be shown (though we will not do it here, to keep the exposition a bit shorter) that - to does not obey the locality constraint of Hamblin indefinites, which is "Associate with the nearest alternative quantifier".

In order to arrive at a somewhat complete CF analysis, we must answer following questions:

(10) 1. Are -to indefinites CF only or they are CF/GQ ambiguous?

2. Where is the CF located (if present)?

3. What is the contribution of $-t o$ ?

Not all possible combinations of answers to the questions in (10) are equally defendable. The answer to (10.1) determines how we should answer other questions. Let us examine both possible lines and their predictions.

The first line is to accept that -to pronouns are not always CFal. If that is the case, they are parallel to $a$ indefinites in English. A CF is a silent lexeme that optionally applies on some level of sentence composition (in our case, the only suitable place where a CF can appear is a sister of the pronoun itself). When this lexeme is present, - $t o$ indefinites are choice-functional, and they are not CFal in other cases. The contribution of -to on this approach is completely unclear.

The alternative line is to accept that -to is always CFal. In this case it is not wise to posit a silent lexeme, because such a lexeme will need to be present always, and it is simpler to assume that the CF is inside the pronoun itself. - To pronouns consist of two morphemes - that is, a bare indefinite root, the same as the corresponding interrogative pronoun, and a series marker -to. The CF may be contained in the meaning of either morpheme. However, if the CF is inside the meaning of the root, then all pronouns with the same root (i.e., Negative Concord 
pronouns, free choice pronouns, etc.) must be CFal too, which is clearly impossible $^{3}$. But if the CF is inside the meaning of the -to morpheme, the resulting picture is more natural: first, we know what the contribution of -to is (namely, it is the introduction of.a CF), and secondly, CFality will be a property specifically of -to series.

Now the question is: Which of these two alternative lines is more adequate? The key question is whether there are cases when -to pronouns have non-CFal readings. A good way to test it is to check the interaction of -to and negation. Consider the case of English $a$ and $a$ certain indefinites. The former can be interpreted CFally, but do not need to, while the latter are always CFal (cf. Kratzer 1998). Now note that while it is possible for $a$ indefinites to take scope in the immediate scope of negation, it is impossible for a certain indefinites ${ }^{4}$ :

(11) a. Mary did not buy a certain house.

b. Mary did not buy a house.

OK for (a), (b): $\quad \exists>$ not $\quad$ (There is a house that Mary did not buy.)

* for (a), ${ }^{\text {OK }}$ for (b): not $>\exists \quad$ (Mary did not buy any house.)

Now we can check the interaction between Russian -to and negation. If we find that -to can have narrow scope reading as $a$ in (11) can, then it is not always $\mathrm{CFal}$, and if it cannot, then it is not ambiguous between GQs and CFs but always CFal.

(12) Petja ne zametil kogo-to iz svoix odnoklassnic.

Petja not has-noticed who-TO of his girl-classmates.

OK $\exists>$ not (There is a girl from his class that Petja did not noticed.)

* not $>\exists$ (Petja did not notice any of the girls in his class.)

(12) shows that -to patterns with a certain, and not with $a$, and I conclude ${ }^{5}$ that the right set of answers for the questions in (10) is the second one, repeated below as (13).

(13) 1. -to pronouns are always choice-functional.

2. and 3. The CF is located in the meaning of -to morpheme.

Standard CF accounts of wide-scope indefinites as Reinhart (1997) and Kratzer (1998) assume that a silent CF of type $\langle\langle e t\rangle, e\rangle$ is applied to an $\langle e t\rangle-$ denoting constituent inside the relevant DP. The only domain where choice functions are put to work is DPs, and the only expressions that escape from their islands with the help of CFs are DPs. But we can see from (9) that the same effect can be observed for AdjPs, AdvPs and PPs too. Thus, we need to replace the definition of basic CFs in (14) by a more general definition of Generalized CFs in (15). Unlike basic CFs, GCFs can yield, for instance, a property from a set of properies, as in (9a), or a manner from a set of manners, as in (9c).

$$
\mathrm{f}_{\langle\langle e t\rangle, e\rangle} \text { is a } \mathrm{C}(\text { hoice }) \mathrm{F}(\text { unction }) \text { if } \mathrm{P}_{\langle e t\rangle}\left(\mathrm{f}\left(\mathrm{P}_{\langle e \mathrm{t}\rangle}\right)\right)=1
$$


Now we have all we need to formulate the meaning for -to series marker: to denotes a GCF, and when this GCF-denoting morpheme is combined with a set-denoting wh-word, a choice-functional indefinite pronoun is formed, (16). The GCF in the denotation of the pronoun should either stay free and be supplied by the context (Kratzer 1998) or be existentially closed at some compositional level (Reinhart 1997). We will retum to the issue of the choice between these two options in Section 2.2, so let us remain agnostic for the moment.

(16) a. $[[t o]]_{\langle\langle\tau t\rangle, \tau\rangle}=\lambda \mathrm{p}_{\langle\tau t\rangle} \mathrm{f}(\mathrm{p})$, where $\mathrm{f}$ is a GCF.

b. $\left[\left[k t o-t o\right.\right.$ 'who-TO']] $=\left(\lambda \mathrm{p}_{\langle\tau t\rangle} \cdot \mathrm{f}(\mathrm{p})\right)(\lambda \mathrm{x} \cdot \operatorname{human}(\mathrm{x}))=\mathrm{f}_{\langle\langle\mathrm{et}\rangle, \mathrm{e}\rangle}(\lambda \mathrm{x} \cdot \operatorname{human}(\mathrm{x}))$.

\section{2. -nibud' Indefinite Pronouns: Choice Functions with an Obligatory Skolem} Argument

Unlike -to indefinites, -nibud' indefinites are not grammatical in simple declarative sentences, (17). To be more accurate, they are not grammatical in every simple declarative sentence, (17) vs. (18a). -Nibud' licensers include quantificational DPs as in (18a), quantificational adverbs, (18b), and intensional verbs, (18c), and if-clauses. What these licensers have in common is that all of them introduce tripartite quantificational structures, be it individuals, (18a), situations, (18b), or worlds, (18c), that are quantified over.

$$
\begin{aligned}
& \text { *Petja uvidel kogo-nibud' iz svoix odnoklassnic. } \\
& \text { Petja has-seen who-NIBUD' of his girl-classmates. } \\
& \begin{array}{llll}
\text { a. Každyj mal'čik vstretil kogo-nibud' iz svoix odnoklassnic. } \\
\text { Every boy }
\end{array} \\
& \text { * } \exists \text { > every (There is a girl whom every boy met.) } \\
& \text { OK every }>\exists \text { (For every boy, there is a girl he met.) } \\
& \text { b. Petja často vstrečal kogo-nibud' iz svoix odnoklassnic. } \\
& \text { Petja frequently met who-NIBUD' of his girl-classmates } \\
& \text { * } \quad \exists>\text { frequently (There is a girl whom Petja frequently met.) } \\
& \text { OK frequently }>\exists \text { (Frequently, Pet ja met some girl or other.) } \\
& \text { c. Petja xočet vstretit' kogo-nibud' iz svoix odnoklassnic. } \\
& \text { Petja wants to meet who-NIBUD' of his girl-classmates } \\
& \text { * } \exists>\text { want (There is a specific girl whom Petja wants to meet.) } \\
& \text { OK want }>\exists \text { (Pet ja wants to meet just any girl) }
\end{aligned}
$$

However, even when it is licensed, -nibud' is forced to be in the scope of the licenser. Informally, we can say that the reason why -nibud' is not licensed in simple declarative sentences is that such sentences do not contain any suitable quantificational operator for -nibud' to be in the scope of. What if we have two possible licensers? Then two scopal options will be possible for -nibud' indefinite: it can either have narrow or intermediate scope: 
(19)

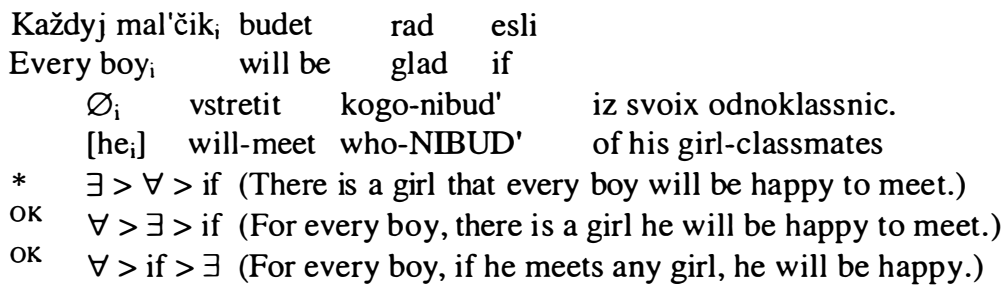

The same (19) shows that -nibud' can scope out of its island, as -to can: under the intermediate reading, -nibud' takes scope over the if-clause it is contained in. The difference, though, is that -to can obtain the widest scope, while -nibud' cannot. As with -to pronouns, we have two options: either CFs or alternatives must be involved in the interpretation of -nibud' indefinites.

On the one hand, -nibud' pronouns resemble Japanese Hamblin pronouns much more than -to pronouns do. -Nibud' needs a licenser, and is forced to be in the scope of this licenser, just as Hamblin pronouns do. However, the locality constraint on alternatives does not hold for -nibud': it can 'skip' the nearest operator, cf. the intermediate reading in (19). Therefore, we have no choice but to accept that CFs are involved in -nibud' interpretation (or, more accurately, Generalized CFs).

\subsection{1. -nibud' Licensing}

When we adopted the CF analysis for -to pronouns, matters were simple, since all scope construals were possible for them. But if we try to provide an analogous analysis for -nibud' indefinites, matters become more complicated, because we need to give an explanation for two facts: 1) -nibud' needs licensing by quantificational operators; 2) -nibud' cannot have a scope wider than that of its (highest) licenser. Though it may seem to be a problem to explain these properties of -nibud', I argue these properties actually provide a new argument in favor of Kratzer-style CFs over Reinhart-style CFs.

Suppose we are to describe the two facts above under Reinhart (1997), who claims that $\mathrm{CF}$ variables are subject to obligatory existential closure that can be applied at any compositional level. We cannot help but make two corresponding stipulations: namely, that -nidud' does need a licenser, and that the existential closure must be applied only at those sites that are in the scope of the licenser. No principled explanation why this should be so can be available. We cannot even explain the fact that the class of -nibud' licensers includes all and only quantificational expressions in natural language.

Under Kratzer (1998), things can be made better. In contrast to Reinhart, Kratzer argues that CFs are not subject to existential closure at all. Instead, they must stay free. A value for a CF is supplied by the context of the utterance just the way the context supplies values for all free variables (i.e., unbound pronouns). As for cases where a CF indefinite takes intermediate (pseudo-)scope, Kratzer (1998) proposes that the relevant reading must be captured not via positing an existential quantifier over CFs at some intermediate compositional level, but via 
Skolemization of a CF. A Skolemization operation adds an argument to a CF; thus a choice from the set denoted by the argument of our CF is relativized: the function can pick different individuals from the set for different values of the additional argument. It is exactly what we need to capture intermediate readings: the Kratzer-style meaning using Skolemization in (20c) is logically equivalent to the Reinhart-style meaning using existential closure for choice functions in (20b). Of course, Skolemization can be applied more than one time, in order to derive narrow scope readings for more embedded CF indefinites.

(20) a.Every girl kissed a certain boy.
b. Reinhart-style: $\quad \forall \mathrm{x} \operatorname{girl}(\mathrm{x}) \exists \mathbf{f}(\operatorname{kissed}(\mathrm{f}(\mathrm{boy}))(\mathrm{x}))$
c.Kratzer-style: $\quad \forall \mathrm{x} \operatorname{girl}(\mathrm{x})(\operatorname{kissed}(\mathrm{f}(\mathrm{x}$, boy $))(\mathrm{x}))$

To account for -nibud' properties, we need to use an additional stipulation. This stipulation is a rather costly one, namely, it says that Skolem arguments are not the same variables as overt pronouns denote, and are not subject to the usual variable binding mechanism. While pronouns can be bound by both quantifiers and individual-denoting expressions, I argue that for Skolem arguments, only quantificational operators are proper binders, and that individual-denoting DP binding is excluded. How can this stipulation help us to account for -nibud' properties?

How will a CF indefinite with an already added Skolem argument behave, if we accept that only quantifiers can bind Skolem arguments? First, we will need to satisfy the argument requirement, and our Skolemized CF will need to find a binder in some c-commanding position. If such a binder does not exist, the Skolemized CF will not be licensed, since its argument is left unbound. And if we have found a quantifier that binds the Skolem argument, the resulting interpretation is equivalent to the interpretation where the $\mathrm{CF}$ is existentially closed in the immediate scope of the quantifier. In other words, a CF that is obligatorily Skolemized will have two peculiar properties: first, it will need to have a quantifier as a licenser; secondly, it will seem to us that it must always be in the scope of its licenser.

That is exactly how -nibud' behaves. The need for a licenser is just the need for a proper binder. The (pseudo-)scope of -nibud' in the resulting interpretation cannot be wider than the scope of its licenser because binding the Skolem argument of a CF by a quantifier is equivalent to having this CF existentially closed in the scope of this quantifier.

Just like the meaning of -to, the meaning of -nibud' is a Generalized CF. However, -to denotes an 'unmarked' GCF, while -nibud' denotes a GCF that is already Skolemized for one argument.

What is the type of the Skolem argument -nibud' has? It seems that a quantifier over any natural language type is enough to license -nibud'. Thus, in order to get proper licensing conditions, we must accept that Skolemization is polymorphic, and the meaning for-nibud' looks like this:

a. $\left[\left[\text { nibud }^{\prime}\right]\right]_{\langle\langle\tau\rangle,\langle v \tau\rangle)}=\lambda \mathrm{p}_{\langle\tau \tau\rangle} \lambda \mathrm{x}_{v} \cdot[\mathrm{f}(\mathrm{x}, \mathrm{p})]$, where $\mathrm{f}$ is a GCF. 


$$
\text { b. } \begin{aligned}
{\left[\left[k t o-n i b u d^{\prime}\right]\right]=\left(\lambda \mathrm{p}_{\langle\tau\rangle} \lambda \mathrm{x}_{v} \cdot \mathrm{f}_{\langle\langle\tau\rangle\rangle\langle\langle\tau\rangle\rangle}(\mathrm{x}, \mathrm{p})\right)(\lambda \mathrm{y} \cdot \operatorname{human}(\mathrm{y}))=} \\
=\lambda \mathrm{x}_{v} \cdot \mathrm{f}(\mathrm{x}, \lambda \mathrm{y} \cdot \operatorname{human}(\mathrm{y})) .
\end{aligned}
$$

This straightforward analysis looks nice, but in order to arrive at it, we rejected the idea that binding of Skolem arguments is the same as familiar overt pronoun binding. In the absense of independent positive evidence in favor of this decision, is it not too costly to accept that we have two different binding mechanisms?

\subsection{Skolem Argument Binding}

The conceptual problem with our stipulation that only quantifiers can bind Skolem arguments is that it states there are different binding mechanisms for different bindees (namely, Skolem arguments and overt pronouns). However, let us note that if we take seriously ideas of File Change Sematics and Discourse Representation Theory, then we accept that there are at least two different kinds of variables and two binding mechanisms, since discourse referent variables introduced by indefinites are different from those introduced by pronouns. Namely, the latter can be unselectively bound, while the former cannot, (22). Thus our stipulation adds not the second type of binding, but the third type. It does not mean to say that having many different types of binding is a good thing; but if we allow for different binding mechanisms for indefinites and anaphoric pronouns, why not allow for another one for Skolem arguments, while hoping that whatever solves conceptual problems of allowing two types of binding will equally well solve problems of allowing three types?

(22) a. John did not buy a house. ${ }^{\mathrm{OK}}=$ 'John did not buy any house'

b. John did not buy it. $\neq$ 'John did not buy anything'

Besides this purely conceptual problem, we need to make sure if we preserve the welcome results of Kratzer (1998), who uses individual binding for Skolem arguments. To be accurate, Kratzer (1998) uses individual binding only in one case, that is, she argues that when the covert variable of a certain is not bound by any quantificational operator, it has the speaker as its value. Kratzer hopes to capture the insight of Hintikka (1986) that way. This insight concerns the difference in truth conditions of (23a) and (23b). Suppose the speaker intends to construe the indefinites in both (23a) and (23b) as 'specific'. For instance, he may think of a specific individual while uttering (23a) and (23b). However, if it happens that there is a man walking in the park, but he is not that specific person the speaker thought of, (23a) will still be true, but (23b) will not. The conclusion to draw from this example is that a certain indefinites are somehow related to the speaker's actual beliefs, while $a$ indefinites are not. Kratzer hopes that if the value of the Skolem argument of a certain in (23b) is the speaker, we can capture this insight. 
(23) a. A man is walking in the park. (He is tall.)

b. A certain man is walking in the park. (He is tall.)

However, Kratzer's account cannot capture the insight. In both (24a) and (24b), the context provides a value for $\mathbf{f}$. If we do not use the speaker argument, as Kratzer would argue, we cannot make sure that the value chosen will be the actual individual that the speaker thought of. For instance, the context can supply a function $f_{l}(p)$ such that $f_{1}$ picks the individual that the speaker thinks of, which is right, but it can equally well supply a function $f_{2}(p)$ that will hold, say, of some friend of the addressee, and that is not the right function, if we want to derive the actual meaning for (23b). But in the case of the function (24b) that uses the speaker argument, it is just the same, as Breheny (2003) notes. The only difference between (24a) and (24b) is that the latter function chooses a value that is somewhat relative to the speaker of the utterance. Now suppose that the context supplies the function $f_{3}(x, p)$ where $f_{3}$ chooses the individual of which $p$ holds and such that $x$ 'has in mind' this individual. This function $f_{3}$ will allow us to derive the right truth conditions. However, the context, again, may equally well supply a function $\mathrm{f}_{4}(\mathrm{x}, \mathrm{p})$ that will choose the individual of which $\mathrm{p}$ holds and such that $\mathrm{x}$ hates this individual the worst. As $f_{1}$ will do while $f_{2}$ will not, $f_{3}$ will do while $f_{4}$ will not. So we have no reason to use (24b) instead of (24a): It cannot help us to derive the right meaning for (23b) with a certain.

(24) a. $\quad \mathbf{f}(\lambda x \cdot \operatorname{man}(x))$

b. $\quad \mathbf{f}(\operatorname{speaker}, \lambda x \cdot \operatorname{man}(x))$

But is there a way to capture Hintikka's insight? I argue we can find a solution by examining one more problem for the contextualist account of Kratzer (1998). Kratzer argues that the context directly supplies values for CF variables. However, as Breheny notes, contextually-supplied values (i.e., values of unbound overt pronouns) are usually presupposed to be known to both the speaker and the addressee (cf. he in 'He left'), but that is not the case for choice functions involved in the interpretation of indefinites: As a rule, only the speaker knows the function, not the addressee. We have the two problems so far: 1) we need to capture the relation to the speaker in $(23 b) ; 2)$ it does not seem like the context provides the value for a CF directly, as in the case of overt pronouns.

There is a simple and elegant solution under a Kratzer-style CF approach that allows us to solve both problems at the same time. Instead of leaving our CF free, we can add a condition on it that requires that the speaker must know the CF, (25). The first problem is solved, because now it is the speaker that decides which function is used, not just the context. The second problem is solved too, since the context does not provide the value directly.

Another welcome consequence of our improvement is that now we can safely ban individual binding of Skolem arguments, since we do not need the speaker argument anymore, and that in turn allows us to use our stipulation from the previous section to account for-nibud' pronouns in Russian. After the improvement, our meanings for -to and -nibud' look like this: 
(25) a. $[[t o]]_{\langle\langle\tau\rangle, \tau\rangle}=\lambda \mathrm{p}_{\langle\tau t\rangle} \cdot[\mathrm{f}(\mathrm{p})], \mathrm{f}$ is a GCF, and know(f, speaker).

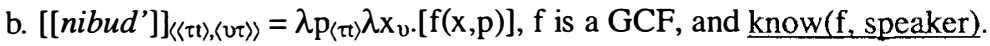

After we have modified our meaning this way, the context still plays a role in interpreting -to, since the condition we added is relative to the speaker of the utterance, but this kind of contextualism does not lay on the addressee the burden of identifying the value. This analysis is analogous to the proposal in Breheny (2003), who formulates the rule for a certain roughly as (26) (I have oversimplified Breheny's original (16) for the sake of exposition) ${ }^{6}$ :

(26) certain denotes an identifying property $P$ such that the speaker of the utterance $U$ knows this identifying property $P$.

\section{Choice-functional Series: an (Intermediate) Summary}

We have examined two series of indefinite pronouns in Russian and arrived at a purely semantic analysis that accounts for their distribution and interpretational possibilities. Under our analysis, both series markers denote generalized choice functions. -to denotes a basic GCF, while -nibud' denotes a GCF that is already Skolemized for one argument. Thus, we have made another step towards explaining differences among indefinite series in natural languages described in Haspelmath (1997), providing an explicit account predicting the distribution and interpretation of the two Russian pronoun series on semantic grounds.

Moreover, comparing analyses for -nibud' data under the Reinhart (1997) and Kratzer (1998) proposals for choice functions, we concluded that our data provides a strong empirical argument for the use of Kratzer-style choice functions, provided that we make necessary improvements. Along with the evidence in Schlenker (1998), Mattewson (1999), and Kim (2003), a.o., this argument provides further support for the (modified) analysis of Kratzer (1998) ${ }^{7}$.

However, if our account is on the right track, then the proposal of $\mathrm{K} \& S$ (2002) that all indefinite pronoun series differences can be explained as agreement differences cannot be maintained: first, -to and -nibud' indefinite pronouns are not alternative-inducing; secondly, our analysis derives their properties using not some syntactic agreement features they carry, but their meanings. Thus, K\&S2 does not hold: it may be true that there are Hamblin pronouns with their series markers carrying meaningless agreement features, but there are other types of indefinite pronouns as well, having meaningful markers.

However, what about K\&S1? The analysis so far presupposed that indefinite roots denote sets (be it sets of individuals, sets of properties, etc.) And if we believe that K\&S's analysis for Japanese is right (and there are very good reasons to believe it), then we get the following picture: While Japanese indefinite pronoun roots denote Hamblin sets, Russian ones denote mere sets. Is this a parameter that can be set differently in different languages, or is it just an artifact caused by the way one of the analyses is formulated? 
In the next section I show that the two accounts can be easily unified once we reject the assumption that a choice function takes as its argument a set. I argue that CFs denoted by -to and -nibud' take not sets, but Hamblin set as arguments.

\section{Hamblin Indefinite Pronouns in Russian}

K\&S (2002) convincingly argued that Japanese bare indefinite roots denote Hamblin alternative sets, while we assumed that Russian indefinite roots denote usual properties that can serve as arguments for GCFs denoted by -to and -nubud'. There are three logical cases:

(27) 1. Japanese and Russian indefinite roots can denote different things, and our account cannot be unified with the $K \& S$ account;

2. $\mathrm{K} \& \mathrm{~S} 1$ is not true, and Japanese pronoun roots denote not Hamblin sets, but usual sets (properties);

3. Russian and Japanese indefinite pronoun roots denote Hamblin sets.

The first option is unsatisfying on conceptual grounds. It may serve as a last resort, but only in the case we fail to maintain (27-2) or (27-3). If we accept the second option, we need to explain peculiar properties of Japanese indeterminate pronouns not in a way $K \& S$ do, which does not seem an easy task. If we accept the third one, we need to accept that choice functions denoted by -to and -nubud' take Hamblin sets instead of usual properties as their arguments.

How can we find empirical evidence to tease apart these options? Hamblin pronouns have four important properties:

(28) H1: Hamblin pronouns need a licenser. They always (pseudo)scope in the immediate scope of their licenser.

H2: Hamblin pronoun licensers are alternative quantifiers.

H3: The pseudoscope of Hamblin pronouns is island-insensitive.

H4: Hamblin pronouns must associate with the nearest licenser.

If we can find a Russian pronoun series having these properties, we will have a good empirical reason to think that Russian indefinite roots denote Hamblin alternative sets. I argue that there is indeed a series having these properties: the bare indefinite series.

This series of indefinite pronouns looks the same as the interrogative series, but the two have different interpretational possibilities. While (29a), hosting an interrogative pronoun, is a typical wh-question, (29b), hosting a bare indefinite, is a yes-no question, and the pronoun seems to be an indefinite that is existentially closed in the scope of the question.

(29) a.Kto prišel?

who came

'Who came?' 
b. Razve kto prišel? is-it-true-that who came 'Is it true that someone came?'

* $\exists>\mathrm{Q} \quad$ (The question is about some specific person.)

OK $\mathrm{Q}>\exists \quad$ (The question is whether just anyone came.)

Though bare indefinites and interrogatives look the same, the pronoun in (29a) (under the neutral question intonation) cannot have an indefinite interpretation. If bare indefinites and wh-words are homonymous, why can (29a) not be understood as containing a bare indefinite? That is because bare indefinites need licensing (razve in (29b) is such a licenser). Moreover, even when bare indefinites are licensed, they take scope under their licensing operator:

(30) a. Particles forming yes-no questions:

Ne prixodil li kto?

not came Q who

'Did anyone come?'

b. If-clauses:

Esli kto pridet, zovi menja.

if who come call me

'If anyone comes, call me.'

c. Subjunctive clauses:

Petja zaper dver' čtoby kto ne vošel.

Petja locked the door that-SUBJ who not come in

'Petja locked the door in order that anyone cannot come in.'

d. (Some) epistemic operators:

Možet, kto prixodil.

It may be that who came

'It may be that someone came.'

In all cases, bare indefinites scope under their licensers. Moreover, they have to be in the immediate scope of their licensers: consider (31). The universally quantified DP každyj mal'čik 'every boy' cannot license the bare series, cf. (31a) where the pronoun only can be the interrogative one, while razve 'is-it-true-that' can license bare indefinites, (29b). However, we can check whether both scope possibilities with respect to the universally quantified DP in (31b) are possible for bare indefinites. If bare indefinites are something like usual GQs, it should be so, but if they are Hamblin pronouns, only the intermediate scope possibility will be available in (31b).

(31) a. Každyj mal'čik videl kogo.

every boy saw who

* $\forall>\exists \quad$ 'Every boy saw someone'

OK who $>\forall$ 'Who did every boy see?', non-functional

OK $\forall>$ who 'Who did every boy see?', functional 
b. Razve každyj mal'čik videl kogo?

is-it-true-that every boy saw who

$* \exists>\mathrm{Q}>$ every

'There is a person, and is it true that every boy saw this person?' ${ }^{\mathrm{OK}} \mathrm{Q}>\exists>$ every

'Is it true that there is a person that every boy saw?'

$* \mathrm{Q}>$ every $>\exists$

'Is it true that every boy saw some person or other?'

The data in (31) shows the bare series has the property $\mathrm{H} 1$, and thus are the candidates to be considered if we want to find Hamblin pronouns in Russian. What about other properties of Hamblin pronouns?

(32) shows that the bare series is in fact island-insensitive, so $\mathrm{H} 3$ holds. And (33) shows that $\mathrm{H} 4$ holds too, since the bare series cannot skip the nearest licenser.

(32) Razve Petja čitaet knigu kotoruju kto uže bral? Is-it-true-that Petja reads a book that who already took? 'Is it true that Petja read the book that someone (just anyone) had borrowed before (from the library)?'

(33) Razve Petja ujdet esli kto pozvonit? Is-it-true-that Petja will-leave if who calls? * $\quad \exists>$ if (There is a person $x$ such that Petja will leave if $x$ calls) OK if $>\exists$ (If whoever calls, Petja will leave)

We have good reasons to believe that the bare series are Hamblin pronouns! The only thing that we have not confirmed yet is that bare series licensers are all and only alternative quantifiers in Russian. However, it is not easy to confirm this: After all, the only stable diagnostic we can use is the ability to catch alternatives induced by Hamblin pronouns. In order to know whether the bare series are Hamblin, we need to check whether their licensers are alternative quantifiers; in order to check whether these licensers are alternative quantifiers, we need to make sure they can license Hamblin pronouns.

Maybe we can get some indirect evidence? For instance, it may happen that the class of alternative quantifiers is cross-linguistically stable, and that Russian bare series licensers belong to this class. Unfortunately, it is not the case.

The bare series licensers in Russian do not form any existing natural class. Why some expressions are such licensers while others are not is a complete mystery. To get a taste of it, compare (30d) and (34): Both have epistemic operators, but only možet 'it-may-be', and not dolžno byt' 'it-is-likely', can license the bare series ${ }^{8}$ :

*Dolžno byt', kto prixodil.

It is likely that who came

'It is likely that someone came.' 
And even worse, some other Indo-European languages have bare indefinite series too; such series always need licensing, but actual members of the class of bare series licensers vary (Haspelmath 1997, pp.170-4). E.g., Slovene and Byelorussian allow bare pronouns in imperatives, while Russian does not.

Since it does not seem that the class of licensers is cross-linguistically stable, we need to account for this fact somehow. The fact that Russian does not have any special expression licensing the bare series but use rather common operators instead should be accounted for too. The following solution will do the work: Let us assume that licensers are just "normal" expressions, not alternative quantifiers. However, the grammar of a given language may contain lexicalshifting rules like (35). The expression on the left side in (35) wants a mere proposition as its argument. The expression on the right side receives a Hamblin alternative set argument, then applies an existential propositional quantifier $\exists_{\mathrm{p}}$ to it (this yields a singleton set of propositions), and then apply the 'old' meaning, the meaning from the left side, to the only proposition in the singleton set. Since such rules are lexeme-specific, it is normal that different languages have different shifts. Of course, it is just a description of facts, and much more work is needed to arrive at a more explanatory account.

$$
\begin{aligned}
\lambda \mathrm{p}_{\langle s t\rangle} \cdot[ & {[\text { možet }]](\mathrm{p}) \Rightarrow \lambda \mathrm{P}_{\langle\mathrm{ST}\rangle} \cdot[[\text { možet }]]\left(\exists_{\mathrm{p}} \mathrm{P}\right) } \\
& \text { where } \exists_{\mathrm{p}} \text { is a propositional quantifier defined as in } \mathrm{K} \& \mathrm{~S}(2002): \\
& {\left[\left[\exists_{\mathrm{p}} \alpha\right]\right]^{\mathrm{w}, \mathrm{g}}=\left\{\lambda \mathrm{w}^{\prime} \cdot \exists \mathrm{p}\left[\left(\mathrm{p} \in[[\alpha]]^{\mathrm{w}, \mathrm{g}}\right) \& \mathrm{p}\left(\mathrm{w}^{\prime}\right)=1\right]\right\} . }
\end{aligned}
$$

In any way, even if we do not have any clearer evidence about the nature of the class of licensers, and thus $\mathrm{H} 2$ diagnostic is of little help for us, the three other properties in (28) are enough to prove that the bare series is Hamblin: If we accept the Hamblin analysis, we get these properties for free, and if we do not, we must find a way to derive them. What consequences does our finding that Russian has Hamblin indefinite pronouns have? We have confirmed that bare indefinite roots in Russian denote Hamblin sets, just as Japanese indefinite roots do, and have arrived at the point where we can unify the Japanese and Russian analyses.

The only technical problem that is left is that our GCFs want properties as their arguments, not Hamblin sets. The solution for this problem is simple: We need to replace our Generalized CFs by Hamblin CFs.

(36) $f_{\langle T, \tau\rangle}$ is a Hamblin GCF if $\left(f\left(p_{\langle T\rangle}\right)\right) \in p_{\langle T\rangle}$.

(37) a. $[[t o]]_{\langle\mathrm{T}, \tau\rangle}=\lambda \mathrm{p}_{\langle\mathrm{T}\rangle} .[\mathrm{f}(\mathrm{p})], \mathrm{f}$ is a Hamblin CF , and the speaker knows $\mathrm{f}$.

b. $\quad\left[\left[\right.\right.$ nibud' $\left.^{\prime}\right] \mathrm{k}_{\langle\mathrm{T},\langle\mathrm{v} \tau\rangle)}=\lambda \mathrm{p}_{\langle\mathrm{T}\rangle} \lambda \mathrm{x}_{\mathrm{v}}$. $[\mathrm{f}(\mathrm{x}, \mathrm{p})]$, $\mathrm{f}$ is a Hamblin CF, and the speaker knows $\mathrm{f}$.

(38) a. $\quad[[k t o-t o]]=\lambda \mathrm{p}_{\langle\mathrm{T}\rangle} \cdot\left(\mathrm{f}_{\langle\mathrm{T}, \tau\rangle}(\mathrm{p})\right)\left(\{\mathrm{x}: \operatorname{human}(\mathrm{x})\}_{\langle\mathrm{E}\rangle}\right)=\mathrm{f}_{\langle\mathrm{E}, \mathrm{e}\rangle}(\{\mathrm{x}: \operatorname{human}(\mathrm{x})\})$.

b. $\quad\left[\left[k t o-n i b u d^{\prime}\right]\right]=\lambda \mathrm{p}_{\langle\mathrm{T}} \lambda \mathrm{x}_{\mathrm{v}} \cdot\left(\mathrm{f}_{\langle\mathrm{T},\langle\mathrm{v \tau}\rangle\rangle}(\mathrm{p})\right)\left(\{\mathrm{y}: \operatorname{human}(\mathrm{y})\}_{\langle\mathrm{E}\rangle}\right)=$

$$
=\lambda x \cdot\left(f_{\langle E,\langle v, e\rangle)}(x,\{y: \operatorname{human}(y)\})\right) \text {. }
$$




\section{Open Issues}

Just as is usual for semantic analyses for indefinites, many open issues remain. For instance, one of the major problems is whether we can find some stable diagnostic that will help to determine whether some expression is an alternative quantifier or not, or their interaction with Hamblin pronouns is the only possible test? Independently of this question, a mystery concerning the exact class of Russian bare indefinite licensers should be solved.

The other important set of problems is related to the unification of our proposal and the familiar CF proposals of Reinhart (1997) and Kratzer (1998). Namely, what is the relation between basic CFs and Hamblin CFs? Do we have both, or are basic CFs a specific case of Hamblin CFs? If yes, what specific case, and if not, then why do we have two similar, but slightly different mechanisms?

Thus, introduction of generalized CFs, obligatorily Skolemized CFs and, finally, Hamblin CFs have not decreased the overall number of puzzles about indefinites. Rather, it has uncovered some new problems. Just as most semantic works on indefinites do.

\section{Endnotes}

*I thank the audience of Barbara H. Partee's seminar at Moscow State University, and the members of Moscow Formal Semantics Reading Group, for their valuable comments and stimulating discussion on earlier stages of this paper, and the audience at SALT 15, especially Y. Bronnikov, C. Dobrovie-Sorin, J.M. Gawron, E. Lutikova, E. Rudnitskaja, and I. Zaxarjaschev, as well as two anonymous reviewers for SALT. Many thanks to E. Bylinina, O. Fedorova, B.H. Partee, and S. Tatevosov for their generous help and their constant willingness to discuss the issues and analyses in this paper. Of course, all remaining errors are mine. This material is based upon work supported in part by the National Science Foundation under Grant No. BCS-0418311 to B.H. Partee and V. Borschev, and by the Russian Fund for Basic Research under grant 05-06-85510-3 to I. Yanovich.

'Kogda-to 'when-TO' can hardly receive an analogous interpretation, probably due to the interference of a 'conventional' meaning 'very long ago'.

${ }^{2}$ It will be clear in Section 2 that esli 'if' can serve as an alternative quantifier in Russian. Since -to in (9) can scope over esli 'if', it does not obey the Hamblin locality constraint.

${ }^{3}$ The most striking case is negative indefinite pronouns that are formed from the same indefinite roots. Such a pronoun in (i) cannot scope over the negation, let alone over the island. Thus, it is clearly not a choice-functional indefinite pronoun.

(i) Petja kupil vse masiny kotoryje nikomu ne nravilis'. Petja bought all the cars that no one NEG liked.

* $\exists>$ all $>$ not 'for a certain man, all the cars that man did not like'

* all $>\exists>$ not 'all the cars some man or other did not like'

OK all $>$ not $>\exists$ 'all the cars no one liked' 
${ }^{4}$ Under Kratzer (1998), the inability to be in the scope of negation follows from the ban on unselective binding for pronominal elements. Under Reinhart (1997), some additional stipulation is needed, see Winter (2005) for such an analysis.

${ }^{5}$ If you do not believe the negation argument, you can safely wait for the next section, where we will encounter a different pronoun series that is CFal as -to series is, but has rather different properties. Then it will become clear that if CFs are not contained in series marker meanings, we cannot derive the differences between these two Russian series, because their markers are the only thing that is not the same for the two series.

6The definition in (26) implies that a certain denotes an identyfying property, not a CF. Von Fintel (1999), Schwarzschild (2002) and Breheny (2003), a.o., have argued that choice functions used in Reinhart (1997) and Kratzer (1998) should not be used and that covert domain restriction should be used instead. Under this kind of approach, identifying properties (that is, properties that hold of exactly one object) replace CFs. I do not discuss important differences between the CF and domain restriction approaches in this paper. Suffice it to note that if the domain restriction approach and not the CF approach is right, it is easy to reformulate the analyses in Section 2. Under this kind of approach, -to and -nibud' would denote ('generalized') identyf ying properties, not generalized CFs, but all crucial results of the analysis in this paper will be preserved.

${ }^{7} \mathrm{~A}$ problem is left for this analysis. It is the fact that indefinites do show readings equivalent to those that can be obtained by applying existential closure in the immediate scope of downward-entailing operators, as shown in Chierchia (2001) and Schlenker (2004). However, as Schwarz (2004) shows, not all wide-scope indefinites are able to do this (namely, some can have the relevant reading while $a$ certain cannot). Thus, the evidence of Chierchia (2001) and Schlenker (2004) does not hold for all indefinite types. If CF existential closure were the source of the problematic readings, then why these readings are not possible for all CF indefinites? There must be some other mechanism producing Chierchia effects. If that is the case, the problematic DE data are not a threat to Kratzer-style theories. ${ }^{8} \mathrm{~A}$ similar contrast holds for any, see Dayal (1998). However, any is also licensed in deontic modality contexts, where the bare series are never licensed, so the explanation for any cannot be straightforwardly extended to the bare series.

\section{References}

Breheny, Richard: 2003, 'Exceptional-scope Indefinites and Domain Restriction', in M. Weisgerber (ed.) Proceedings of the Conference "sub7 - Sinn und Bedeutung".

Bylinina, Elisaveta \& Yakov Testelets: 2004, 'On Sluicing-based Indefinites', in S. Franks, F. Gladney, and M. Tasseva-Kurktchieva (eds.) Proceedings of FASL 13, Michigan Slavic Publishers, Ann Arbor, MI. 
Chierchia, Gennaro: 2001, 'A puzzle about Indefinites', in C. Cecchetto, G. Chierchia and M. T. Guasti (eds.), Semantic Interfaces: reference, anaphora and aspect, CSLI Publications, Stanford.

Dayal, Veneeta: 1998, 'ANY as Inherently Modal', Linguistics \& Philosophy 21, 433-476.

Farkas, Donka: 2002, 'Varieties of Indefinites', in B. Jackson (ed.), Proceedings of SALT 12, CLC Publications, Ithaca.

von Fintel, Kai: 1999, 'Quantifier domains and pseudo-scope', talk at Cornell Context-Dependence Conference.

Fodor, Janet. D. \& Ivan Sag: 1982, 'Referential and Quantificational Indefinites', Linguistics and Philosophy 5, 355-398.

Haspelmath, Martin: 1997, Indefinite pronouns, Oxford University Press, Oxford.

Hintikka, Jaakko: 1986, 'The Semantics of a certain', Linguistic Inquiry 17, 331336.

Kim, Ji-yung: 2003, "'Intermediate Scope" in (Mandarin) Chinese', in R. Young and Y. Zhou (eds.), Proceeding of SALT 13, CLC Publications, Ithaca.

Kratzer, Angelika: 1998, 'Scope or Pseudoscope? Are There Wide Scope Indefinites?' in S. Rothstein (ed.), Events and Grammar. Kluwer, Dordrecht.

Kratzer, Angelika \& Junko Shimoyama: 2002, 'Indeterminate Pronouns: The View from Japanese', in Y. Otsu (ed.), The Proceedings of the Third Tokyo Conference on Psycholinguistics, Hituzi Syobo, Tokyo.

Matthewson, Lisa: 1998, 'On the Interpretation of Wide-scope Indefinites', Natural Language Semantics 7, 79-134.

Reinhart, Tanya: 1997, 'Quantifier Scope: How Labor Is Divided between QR and Choice Functions', Linguistics and Philosophy 20, 335-397.

Schlenker, Philippe: 1998, 'A Note on Skolem Functions and the Scope of Indefinites', ms.

Schlenker, Philippe: 2004, 'Scopal Independence: On Branching and Wide-scope Readings of Indefinites and Disjunctions', ms.

Schwarz, Bernhard: 2004, 'Indefinites in Verb Phrase Ellipsis', Linguistic Inquiry 35, 344-355.

Schwarzschild, Roger: 2002, 'Singleton Indefinites', Journal of Semantics 19, 289-314.

Shan, Chung-Chieh: 2004, 'Binding alongside Hamblin Alternatives Calls for Variable-free Semantics', in R.B.Young (ed.), Proceedings of SALT 14, CLC Publications, Ithaca.

Shimoyama, Junko: 2001, Wh-Constructions in Japanese, Ph.D, UMass.

Winter, Yoad: 2005, 'On Some Problems of (In)definiteness within Flexible Semantics', Lingua 115, 767-786. 